Int. J. Dev. Biol. 55: 431-437

doi: $10.1387 / \mathrm{ijdb} .103221 \mathrm{pm}$

\title{
Hemangiomas - current therapeutic strategies
}

\author{
PEACE MABETA*,1 and MICHAEL S. PEPPER ${ }^{2,3}$ \\ Departments of ${ }^{1}$ Physiology and ${ }^{2}$ Immunology, Faculty of Health Sciences, University of Pretoria, South Africa and \\ ${ }^{3}$ Department of Medical Genetics and Development, University Medical Centre, Geneva, Switzerland
}

\begin{abstract}
Hemangiomas are benign neoplasms of the vasculature frequently encountered in children. Several studies have shown that these tumors are characterized by excessive angiogenesis. Although benign, the lesions can present with complications, and may thus require treatment. There are multiple therapeutic options available for patients with problematic or life threatening hemangiomas, some of which have serious side effects. Randomized clinical trials and evidencebased studies on the efficacy of these treatments is still lacking. The recognition that excessive angiogenesis underlies hemangiogenesis offers an opportunity for the development of safer therapeutic strategies that are based on the inhibition of angiogenesis. We review medical therapies currently employed in the management of hemangiomas and the role of angiogenesis inhibition in hemangioma therapy.
\end{abstract}

KEY WORDS: hemangioma, anti-angiogenesis, bleomycin, vincristine, propranolol

\section{Introduction}

Hemangiomas are benign neoplasms of the vasculature (Mulliken et al., 1982; North et al., 2002). These lesions, often referred to as infantile hemangiomas $(\mathrm{IH})$, are considered to be the most common tumors of infancy (Mulliken and Glowacki, 1982; Sarihan et al., 1997). The incidence of hemangiomas has not been well documented, but it is estimated that one in every ten children develops a hemangioma, most of which are on the head or neck (Mulliken and Glowacki, 1982). The frequency of hemangioma development is increased to $22.9 \%$ for premature infants with a birth weight below $1 \mathrm{Kg}$ (Tan et al., 2000). The clinical appearance of hemangiomas varies with the degree of dermal involvement and the depth of the lesions (Mulliken and Glowacki, 1982). They can have deep, superficial, or mixed components (Bruckner and Frieden, 2003). When the superficial dermis is involved, the skin is usually raised and firm. When the lesion is limited to the deep dermis, subcutaneous tissue or muscle, the overlying skin is raised slightly (Pandey etal., 2009). The degree of dermal involvement has treatment implications in that certain modalities are effective in the treatment of superficial lesions. For instance, in a study involving more than two thousand patients conducted over a period of twenty years, Pandey and co-workers observed that steroid therapy was much more effective in the treatment of superficial hemangiomas (Pandey et al., 2009).
Various vascular tumors have been described in the pediatric population (Table 1), and it appears that $\mathrm{IH}$ differ from these tumors in that they express the glucose transporter GLUT1 (North et al., 2000). Most IH begin their growth in the first few weeks of life (Mulliken and Enjolras, 2004). The lesions have a unique natural history which is divided into three phases, the proliferative phase, the involuting phase and the involuted phase (Mulliken and Glowacki, 1982). The proliferative phase is characterized by rapid growth of the lesion, while during the involuting phase there is a decline in growth, which is followed by the involuted phase or complete regression of the lesion with or without residual sequelae (Mulliken and Glowacki, 1982; Mulliken et al., 1982).

In this paper, we review the current medical therapies that are used in the treatment of hemangiomas. We also discuss the effects of these therapies on the vasculature, and address the future application of antiangiogenic agents in the management of paediatric hemangiomas.

\section{Pathogenesis}

The pathogenesis of infantile hemangiomas is not well understood although both intrinsic and extrinsic theories have been

Abbreviations used in this paper: $\mathrm{IH}$, infantile hemangioma; VEGF, vascular endothelial growth factor; bFGF, basic fibroblast growth factor; MMP, matrix metalloproteinase.

\footnotetext{
*Address correspondence to: Peace Mabeta. P.O. Box 2034, Dept. of Physiology, Faculty of Health Sciences, University of Pretoria, Pretoria 0001, South Africa. Fax: +27-12-529-8305. e-mail: peace.mabeta@up.ac.za
}

Final, author-corrected PDF published online: 27 July 2011.

ISSN: Online 1696-3547, Print 0214-6282

(c) 2011 UBC Press

Printed in Spain 
proposed. The intrinsic theory suggests that the underlying factor in the development of the tumor is a mutation in a critical gene in a precursor stem cell and that the clonal expansion of this single cell carrying a somatic mutation leads to hemangiomagenesis (North, et al., 2002; Regnier et al., 2007).

According to the extrinsic theory, growth factors, an abnormal hormonal milieu, such as increased oestrogen levels, or tissue hypoxia, which leads to increased expression of hypoxia inducible factor (HIF1 $\alpha$ ) and ultimately the stimulation of angiogenesis via vascular endothelial growth factor (VEGF), underlie hemangioma development (Zhang et al., 2008). It is believed that a nascent hemangioma may result from endothelial proliferation secondary to increased levels of growth stimulating factors or decreased levels of growth-inhibitory factors normally present in the tissue (Mulliken and Glowacki, 1982).

Given the fact that hemangiomas are clinically heterogeneous, it is plausible that the tumors are not all due to the same underlying defect; it is also possible that a hemangioma may arise due to a combination of mechanisms explained by both theories. However, there is consensus that the defining feature of $\mathrm{IH}$ is excessive angiogenesis.

\section{Role of angiogenesis}

Hemangioma growth has been described as an example of an angiogenic disease in which an imbalance in normal vascular tissue turnover occurs, and that the increased endothelial proliferation may be caused by abnormal levels of angiogenic stimulators (increased) or inhibitors (reduced) (Mulliken and Enjolras, 2004; Pepper 1997). Light microscopic studies undertaken by Mulliken and Glowacki on hemangioma tissue have demonstrated that the hallmark of the growing hemangioma is endothelial cell proliferation (Mulliken and Glowacki 1982).

In addition, some of the growth factors which mediate the complex stages of angiogenesis, namely VEGF and basic fibroblast growth factor (bFGF), were found to be over expressed in proliferating hemangiomas (Takahashi et al., 1994).

In a separate study, VEGF and high molecular weight matrix metalloproteinases (MMPs) were found to be elevated in urine samples of patients with proliferative hemangiomas (Zhang et al., 2008). Matrix metalloproteinases are involved in the degradation of extracellular matrix components during the angiogenic process (Pepper, 1997). These markers of angiogenesis diminish to normal levels during hemangioma regression (Takahashi et al., 1994). There is also an increase in endothelial cell apoptosis and a decrease in endothelial cell proliferation during the involu-

\section{TABLE 1}

\section{VASCULAR TUMORS OF INFANCY}

\section{Infantile hemangioma $(\mathrm{IH})$}

Rapidly involuting congenital hemangioma ( $\mathrm{RICH})$

Noninvoluting congenital hemangioma $(\mathrm{NICH})$

Tufted angioma

Kaposiform haemangioendothelioma

Pyogenic granuloma (lobular capillary tumors)

Other rare tumors tion of IH (Hasan et al., 2000; Razon et al., 1998). Therefore, therapeutic strategies focused on specific cellular events that occur during angiogenesis may be effective in the treatment of these tumors.

\section{Complications}

Not all hemangiomas require treatment since most are asymptomatic. However, a subset of patients experience serious complications due to the location of the lesion or interference of the lesion with a physiological function (Blei, 2005). For instance, facial hemangiomas can result in disfigurement and feeding difficulties, while subglottic hemangiomas can lead to airway obstruction (Haik et al., 1994).

Other complications include pain, infection, ulceration, and bleeding (Blei, 2005; Cordoro et al., 2009), the latter of which, although rare, can lead to severe anaemia (Blei, 2005). In patients with large hemangiomas, moderate thrombocytopenia is a common occurrence (Martins 1970). According to Martins, the trapping of platelets and other coagulation factors within the hemangioma leads to thrombocytopenia (Martins 1970).

The development of congestive heart failure is another complication that is encountered in infants with hepatic hemangiomas (Boon et al., 1996), and these patients require treatment. It has been reported that without treatment, the mortality for hepatic hemangiomas is as high as $80 \%$, and that early and aggressive treatment can lower mortality to approximately 20\% (Boon et al., 1996).

\section{Treatment}

There have been several reports on the management of both symptomatic and asymptomatic hemangiomas. Thus while there is consensus that problematic hemangiomas require intervention, the management of asymptomatic lesions remains controversial, partly because of the lack of randomized clinical trials that prove the efficacy of commonly used therapies (Barlow et al., 1998). Various therapeutic modalities ranging from surgery to radiation therapy were originally employed in the treatment and management of hemangiomas (Enjolras and Mulliken 1993).

Decompression surgery and radiation therapy were the traditional means for treating lesions causing spinal pain or compression. Surgery is often associated with massive haemorrhage from these highly vascular tumors and is not commonly employed.

Medical therapies have become the mainstay in the management and treatment of hemangiomas (Enjolras and Mulliken 1993; Pandey et al., 2009). The major goals of management of $\mathrm{IH}$ have recently been outlined in the Guidelines of Care for Hemangiomas of Infancy by the American Academy of Dermatology (Frieden et al., 1997) and these include: "(i) the prevention of life-threatening complications or those complications that interfere with physiological function, and the treatment of such complications if they arise; (ii) the prevention of disfigurement due to residual skin changes after the involuted phase; (iii) the minimizing of psychological distress; (iv) avoidance of aggressive potential scarring procedures; $(v)$ the minimizing of scarring, infection and pain." The antiangiogenic effects of the commonly used drugs in the management of hemangiomas are shown in Table 2. 


\section{Steroid therapy}

The efficacy of steroids in the treatment of $\mathrm{IH}$ was initially observed by Zarem and Edgerton, who noted that hemangiomas decreased in size when steroids were used to treat paediatric patients for thrombocytopenia (Zarem and Edgerton 1967). A number of studies have since been published on the efficacy of steroid therapy in the treatment of hemangiomas (Enjolras and Mulliken 1993; Martins 1970; Pandey et al., 2009). One study reported on the use of steroid therapy in 39 hemangioma patients, with an unpredictable outcome (Martins 1970). Growth retardation was a reported side effect; however, there was recurrence of growth after interruption of therapy (Martins 1970). Despite this side effect, steroid therapy has at times proven to be very effective in reducing the size of the lesion and in increasing the number of platelets in patients presenting with thrombocytopenia.

At present, complicated hemangiomas are treated initially with corticosteroids, systemically, topically or intralesionally. Overall, steroids dramatically regresses hemangiomas in a third of the patients, and has little or no effect in the remaining two thirds, with some of the patients showing signs of worsening while still on treatment (Enjolras and Mulliken 1993).

The mechanism of steroid treatment in accelerating hemangioma regression remains unclear; however, a study undertaken by Hasan and coworkers showed that triamcinolone acetonide (TA) inhibits neovessel growth in an in vitro human hemangioma model. Similarly, dexamethasone, another glucocorticoid used in the treatment of hemangiomas, has been shown to inhibit neovessel growth in cultured human hemangioma biopsies; neither VEGF nor bFGF appeared to play a vital role in steroid induced inhibition of capillary growth based on observations in studies undertaken using the human hemangioma model (Hasan et al., 2003).

The effects of both triamcinolone acetonide and dexamethasone appeared to be directly on hemangioma endothelial cells. Triamcinolone acetonide has previously been shown to inhibit VEGF-induced angiogenesis in the rat corneal micropocket assay, and to block interleukin-6 (IL-6) mediated neovascularization in the same assay (Ebrahem et al., 2006). An independent study demonstrated that TA also inhibits angiogenesis in the chorioallantoic membrane (CAM) assay (McKay et al., 2008).

Other glucocorticoids commonly used in the treatment of hemangiomas, such as betamethasone, methylprednisolone and hydrocortisone, had a negligible effect on capillary growth in vitro in the same hemangioma model (Hasan et al., 2003).

The inhibition of neovessel growth in dexamethasone-treated hemangioma biopsy cultures was associated with an increase in the transcription of clusterin/apolipoprotein $\mathrm{J}$ (clust/apo $\mathrm{J}$ ) and increased transcription of the apoptotic gene, mitochondrial cytochrome b (Hasan et al., 2000). Clusterin/apolipoprotein $\mathrm{J}$ is a secreted glycoprotein involved in a number of biological processes and is a marker of apoptosis; it is also associated with hemangioma involution (Hasan et al., 2000). Therefore, induction of endothelial cell apoptosis may play a role in dexamethasoneinduced hemangioma regression. The mechanisms underlying the effects of betamethasone, methylprednisolone and hydrocortisone are yet to be elucidated, although prednisolone has been shown to inhibit angiogenesis in a mouse model (Banciu et al., 2006).

Even though corticosteroid therapy is undoubtedly a useful form of treatment for proliferative infantile hemangioma, it can lead

TABLE 2

\section{ANTIANGIOGENIC EFFECTS OF DRUGS COMMONLY USED IN THE TREATMENT OF INFANTILE HEMANGIOMAS}

\begin{tabular}{|c|c|c|c|}
\hline Drug & Model & Antiangiogenic effects & References \\
\hline \multirow[t]{3}{*}{ Triamcinolone } & Rat corneal micropocket & $\begin{array}{l}\text { Inhibits VEGF mediated angiogenesis } \\
\text { Inhibits IL-6 mediated angiogenesis }\end{array}$ & Ebrahem et al., 2006 \\
\hline & CAM assay & Inhibits angiogenesis & McKay et al., 2008 \\
\hline & Cultured human hemangioma biopsies & Inhibits neovessel formation & Hasan et al., 2003 \\
\hline Dexamethasone & Cultured human hemangioma biopsies & $\begin{array}{l}\text { Inhibits neovessel formation } \\
\text { Increases Clust/Apo J expression } \\
\text { Increases expression of mitochondrial cyt b }\end{array}$ & Hasan et al., 2003 \\
\hline Prednisolone & B16 melanoma in mice & Inhibits angiogenesis & Banciu et al., 2006 \\
\hline \multirow[t]{3}{*}{ Bleomycin } & Bovine microvascular endothelial (BME) cells & $\begin{array}{l}\text { Inhibits endothelial cell growth \& migration } \\
\text { Inhibits in vitro angiogenesis } \\
\text { Induces endothelial cell apoptosis }\end{array}$ & Mabeta and Pepper 2009 \\
\hline & Cultured human hemangioma biopsies & Inhibits neovessel formation & Mabeta and Davis, 2008 \\
\hline & CAM assay & Inhibits neovessel formation & Oikawa et al., 1990 \\
\hline \multirow[t]{3}{*}{ Interferon u61537 } & Skin sections from hemangioma patients & Induces apoptosis & Sgonc et al., 1998 \\
\hline & Nude mice -hepatocellular carcinoma & Inhibits angiogenesis & Wang et al., 2003 \\
\hline & Human brain endothelial cells & $\begin{array}{l}\text { Inhibits capillary-tube formation } \\
\text { Inhibits VEGF secretion }\end{array}$ & Annabi et al., 2009 \\
\hline \multirow[t]{2}{*}{ Thalidomide } & EA.hy 926 cells & Inhibits endothelial cell tube formation & Komorowski et al., 2006 \\
\hline & Rat aorta & $\begin{array}{l}\text { Inhibits neovessel formation } \\
\text { Inhibits VEGF secretion }\end{array}$ & Bauer et al., 1998 \\
\hline \multirow[t]{3}{*}{ Vincristine } & HUVEC & Inhibits capillary network formation & Hayot et al., 2002 \\
\hline & BME cells & $\begin{array}{l}\text { Inhibits endothelial cell growth and migration } \\
\text { Inhibits in vitro angiogenesis } \\
\text { Induces endothelial cell apoptosis }\end{array}$ & Mabeta and Pepper, 2009 \\
\hline & Human leukaemia T cells & Inhibits VEGF secretion & Avramis et al., 2001 \\
\hline \multirow[t]{2}{*}{ Propranolol } & PMA-activated human leukaemia cells & $\begin{array}{l}\text { Decreases VEGF expression } \\
\text { Inhibits angiogenesis }\end{array}$ & Hajighasemi et al., 2009 \\
\hline & Bovine Brain endothelial cells & Down-regulates VEGF and bFGF & D'Angelo et al., 1997 \\
\hline Cyclophosphamide & Lewis lung carcinoma in C57BL6 mice & $\begin{array}{l}\text { Inhibits angiogenesis } \\
\text { Decreases VEGF expression }\end{array}$ & Zhang et al., 2006 \\
\hline
\end{tabular}


to complications such as Cushingoid appearance, hypertension, decreased growth rate and weight gain (Enjolras and Mulliken 1993; Pandey et al., 2008; Pandey et al., 2009). However, in most cases the symptoms tend to resolve following cessation of treatment.

\section{Interferon}

Potentially life-threatening hemangiomas that do not respond to corticosteroids have been treated with interferon $\alpha$ (Barlow et al., 1998). Ezekowitz and co-workers evaluated the effectiveness of interferon $\alpha$ in the treatment of hemangiomas in twenty patients, with a successful outcome. (Ezekowitz et al., 1998). Transient side effects that included fever and neutropenia were observed in this group of patients (Ezekowitz et al., 1998). In another study undertaken more recently, an $85 \%$ success rate in twenty hemangioma patients treated with interferon $\alpha 2 b$ was reported. No major side effects were reported (Jimenez-Hernandez et al., 2008). Interferon's therapeutic effectiveness in the treatment of $\mathrm{IH}$ has been attributed to its antiangiogenic activity (Fotsis et al., 1994; Sgonc et al., 1998). The analysis of skin sections from a hemangioma patient treated with interferon $\alpha$ revealed apoptotic endothelial cells (Sgonc et al., 1998).

The major side effect of interferon is spastic diplegia (Barlow et al., 1998; Enjolras and Mulliken 1993; Grimal et al., 2000). As a result, even though high success rates have been reported with this drug, concerns remain about the risk of developing irreversible neurotoxicity in hemangioma patients treated with interferon.

\section{Vincristine}

Vincristine, a microtubule-disrupting plant alkaloid used in cancer chemotherapy, has also been employed in the treatment for hemangiomas (Enjolras et al., 2004). Reports on the use of vincristine for the treatment of life-threatening hemangiomas characterised by the Kassabach-Merritt Syndrome (KMS) are anecdotal (Enjolras et al., 2004). These 'hemangiomas' associated with $\mathrm{KMS}$, although closely related to $\mathrm{IH}$ delete on the basis of their biological behaviour, have been found to be histologically different from $\mathrm{IH}$, and so the tumors are referred to as kaposiform haemangioendothelioma (KHE) (Enjolras et al., 2008; Fernández et al., 2009).

Concerning 'true' hemangiomas of infancy, only a few case studies have reported on the effectiveness of vincristine in the treatment of such lesions (Perez et al., 1995). Side effects observed in patients following treatment with vincristine were transient (Perez et al., 1995).

Vincristine has antiangiogenic properties that may underlie its effectiveness in the treatment of infantile hemangiomas. In a study using the CAM assay, vincristine had an inhibitory effect on vascularisation. The drug is also a potent inhibitor of endothelial cell growth, migration and in vitro capillary-like tube formation, and induces endothelial cell apoptosis (Mabeta and Pepper, 2009). Only a few studies have reported on the use of vincristine for the treatment of $\mathrm{IH}$. Thus Phase II clinical studies, which are underway and which are aimed at comparing the efficacy of corticosteroids and vincristine in the treatment of hemangiomas, will be useful in providing the necessary data to determine the drug's potential as a second-line treatment.

\section{Bleomycin}

Bleomycin is an antineoplastic antibiotic which is effective against a variety of human neoplasms, particularly head and neck squamous carcinoma, Hodgkin's and non-Hodgkin's lymphomas, and testicular carcinoma (Sarihan et al., 1997). The drug was initially reported by Kullendorf to be an effective form of treatment for complicated cutaneous and massive symptomatic inoperable hemangiomas (Kullendorff, 1997).

Subsequent studies revealed that intralesional bleomycin induces accelerated resolution in hemangioma patients, without severe complications (Muir et al., 2004; Pienaar et al., 2006; Sarihan et al., 1997). Low dose intralesional Bleomycin is commonly used as a sclerosing agent for the treatment of vascular anomalies in China, and has been cited as an effective treatment option for $\mathrm{IH}$, with a good safety record (Yang et al., 2009).

In a prospective study undertaken by the Pretoria Vascular Malformation Study Group, intralesional bleomycin was shown to have a curative effect on $\mathrm{IH}$ (Muir et al., 2004). The study also showed an extremely low side effect profile, with reported complications mainly including local pain and transient flu-like symptoms (Muir et al., 2004).

Ulceration and hyper-pigmentation were also observed in a small percentage of patients (unpublished data). Another study conducted by the Red Cross Children's Hospital in South Africa showed that bleomycin was effective in accelerating hemangioma regression in infants, with a success rate of more than $70 \%$ in the 30 patients who were treated. The only reported side-effect was hyper-pigmentation (Pienaar et al., 2006).

Bleomycin was also reported to be effective in treating hemangiomas when administered in combination with dexamethasone (Yang et al., 2009). In twenty-one hemangioma patients treated with the drug combination, a more than $90 \%$ reduction in tumor size in more than $80 \%$ of the patients was reported (Yang et al., 2009). Although the effectiveness of the treatment was largely attributed to bleomycin, given the fact that both drugs were administered at the same time, and given the fact that the two drugs were previously shown to inhibit angiogenesis in human hemangioma biopsies, the degree to which each drug contributed to the induction of tumor regression is not clear.

The findings from studies on the effects of bleomycin on human hemangioma biopsies in vitro suggest that bleomycin may inhibit hemangioma growth in human patients in part by inhibiting neovascularization (Mabeta and Davis, 2008).

This is corroborated by the observation that bleomycin inhibits growth factor-induced endothelial cell invasion, endothelial cell growth and migration, and also induces endothelial cell apoptosis (Mabeta and Pepper, 2009).

Furthermore, increased apoptosis has been shown to coincide with hemangioma regression (Razon et al., 1998). Thus, the induction of endothelial cell apoptosis by bleomycin, and its inhibitory effect on angiogenesis, may underlie its therapeutic effect in $\mathrm{IH}$.

\section{Propranolol}

Propranolol is a non-selective beta-blocker used in the treatment of cardiovascular diseases such as heart failure and hypertension. The effectiveness of propranolol in the treatment of hemangiomas was reported in 2008 by Léauté-Labrèzeand coworkers following the 
successful treatment of a steroid resistant potentially life-threatening hemangioma with propranolol (Léauté-Labrèze et al., 2008). The favorable outcome led to the treatment of nine hemangioma patients with the drug, with excellent results. Excellent results were also obtained following the treatment of thirty-two hemangioma patients with propranolol (Sans et al., 2009). The drug was well-tolerated and no side effects were reported.

The successful therapeutic effects of propranolol on $\mathrm{IH}$ have been attributed to its inhibitory effects on aspects of the angiogenic process (Léauté-Labrèz et al., 2008). Previous studies have also revealed that propranolol induces apoptosis in microvascular endothelial cells in vitro (Sommers et al., 2002).

The excellent clinical outcome and apparent lack of side effects of this form of treatment has prompted its recommendation as a first line treatment for hemangiomas. Another beta-blocker with similar effects to propranolol, namely nadolol, is currently in phase II clinical trials for the treatment of $\mathrm{IH}$.

\section{Cyclophosphamide}

Cyclophosphamide is a chemotherapeutic drug used to treat certain autoimmune disorders and, together with other chemotherapeutic agents, to treat lymphomas, some forms of leukemia and certain solid tumors. Cyclophosphamide has been employed infrequently to treat hemangiomas (Zvulunov and Metzker, 2002). One study has reported on the effectiveness of the drug in the treatment of life threatening multiple hemangiomas after failure with corticosteroids, and no side effects were observed (Gottschling et al., 2006). In a more recent study, the successful use of cyclophosphamide to treat steroid-resistant hepatic hemangioma was reported (Vlahovic et al., 2009). No serious side effects were observed during three years following treatment. The drug's mechanism of action is not well understood, although its effect on hemangioma may be partly attributed to its antiangiogenic effect (Zhang et al., 2006; Zvulunov and Metzker 2002).

Continuous low-dose cyclophosphamide has been shown to have an antiangiogenic effect, and this effect was enhanced when it was administered in combination with another antiangiogenic agent, ginsenoside Rg3 (Zhang et al., 2006). Cyclophosphamide has been used successfully, in combination with interferon $\alpha$, to treat a complicated hemangioma of the orbit (Wilson et al., 2007).

\section{Thalidomide}

Thalidomide is an inhibitor of angiogenesis that was recently reported to be effective in the treatment of a life-threatening unresectable intracranial hemangioma (Frei-Jones et al., 2008). The main symptoms of toxicity were sleeplessness and constipation. The latter side effect was so severe that treatment had to be discontinued (Frei-Jones et al., 2008). In vitro, thalidomide inhibits VEGF secretion and microvessel formation. It has also been shown to induce the migration of human endothelial cells (Komorowski, 2006). There are concerns about the side effects of thalidomide, and therefore the drug is not employed readily in the treatment of $\mathrm{IH}$. However, thalidomide, in combination with cyclophosphamide, is in phase II trials for the treatment of recurrent pediatric malignancies. Acombination of these two drugs, which have been employed singly to treat complicated hemangiomas, may hold promise in the treatment of the lesions.

\section{Conclusion}

Although there is at present no universally-agreed upon treatment for hemangiomas of infancy, steroid therapy remains the first line of treatment for complicated tumors. Steroids produce variable results, and are largely effective in treating hemangiomas in the proliferative phase. While interferon produces a success rate of $80-90 \%$ in the treatment of these lesions, its debilitating side effect, namely the development of spastic diplegia, precludes its use on a routine basis. Propranolol has been used infrequently and the reported cases on the effectiveness of the drug are few. Cytotoxic chemotherapy, which is generally reserved for malignant disease, has also been used for the treatment of infantile hemangiomas with serious complications. Drugs used in this category include cyclophosphamide, vincristine, bleomycin and pingyangymycin. There is concern about the use of cytotoxic chemotherapy to treat juvenile benign lesions.

Drugs in this review have been shown in various independent studies to inhibit different aspects of the angiogenesis process. This provides the basisfor rational drug design based on the mechanistic pathways that occur in hemangiomas, in order to provide therapies that are targeted and specific. In addition, a multi-targeted drug approach may broaden the efficacy of hemangioma therapies, and may perhaps carry a reduced side effect profile if the drugs can be administered at lower doses. Indeed, dexamethasone and bleomycin have been used in combination for hemangioma therapy, with excellent outcomes. Therefore the application of these and other angiogenesis inhibitors warrants further investigation, with a special focus on dose response and drug combinations.

\section{References}

ANNABI B, LACHAMBRE MP, PLOUFFE K, MOUMDJIAN R, BELIVEAU R. (2009). Propranolol adrenergic blockade inhibits human brain endothelial cells tubulogenesis and matrix metalloproteinase-9 secretion. Pharmacol Res 60: 38-445.

AVRAMIS IA, KWOCK R, AVRAMIS VI. (2001). Taxotere and vincristine inhibit the secretion of the angiogenesis inducing vascular endothelial growth factor (VEGF) by wild-type and drug-resistant human leukemia T-cell lines. Anticancer Res 21: 2281-2286.

BANCIU M, SCHIFFELERS RM, FENS MHAM, METSELAAR JM, STORM G. (2006). Anti-angiogenic effects of liposomal prednisolone phosphate on B16 melanoma in mice. J Control Release 113: 1-8.

BARLOW CF, PRIEBE CJ, MULLIKEN JB, BARNES PD, MACDONALDD, FOLKMAN J, EZEKOWITZRAB. (1998). Spastic diplegia as a complication of interferon alfa2a treatment of hemangiomas of infancy. J Pediatr 132: 527-530.

BAUER KS, DIXON SC, FIGG WD. (1998). Inhibition of angiogenesis by thalidomide requires metabolic activation, which is species-dependent. Biochem Pharmacol 55: 1827-1834.

BLEI F. (2005). Basic science and clinical aspects of vascular anomalies. Curr Opin Pediatr 17: 501-9.

BOON LM, BURROWS PE, PALTIEL HJ, LUND DP, EZEKOWITZ RAB, FOLKMAN J, MULLIKEN JB. (1996). Hepatic vascular anomalies in infancy: A twenty-sevenyear experience. J Pediatr 129: 346-354.

BRUCKNERAL, FRIEDEN IJ. (2003). Hemangiomas of infancy. JAm Acad Dermatol 48: 477-493.

CORDORO KM, SPEETZEN LS, KOERPER MA, FRIEDEN IJ. (2009). Physiologic changes in vascular birthmarks during early infancy: Mechanisms and clinical implications. J Am Acad Dermatol 60: 669-675.

EBRAHEM Q, MINAMOTO A, HOPPE G, ANAND-APTE B, SEARS JE. (2006) Triamcinolone acetonide inhibits IL-6- and VEGF-induced angiogenesis downstream of the IL-6 and VEGF receptors. Invest Ophthalmol Vis Sci 47: 4935-4941.

D'ANGELOG, LEE H, WEINER RI. (1997). cAMP-dependent protein kinase inhibits the 
mitogenic action of vascular endothelial growth factor and fibroblast growth factor in capillary endothelial cells by blocking raf activation. J Cell Biochem 67: 353-366.

ENJOLRAS O and MULLIKEN JB. (1993). The current management of vascular birthmarks. Pediatr Dermatol 10: 311-313.

ENJOLRAS O, SOUPRE V, PICARD A. (2008). Uncommon benign infantile vascular tumors. Adv Dermatol 24: 105-124.

ENJOLRAS O, BREVIÈRE GM, ROGER G, TOVI M, PELLEGRINO B, VAROTTIE, SOUPRE V, PICARD A, LEVERGER G. (2004). Traitement par vincristine des hémangiomes graves du nourrissonVincristine treatment for function- and lifethreatening infantile hemangioma. Arch Pédiatrie 11: 99-107.

EZEKOWITZ RA, MULLIKEN JB, FOLKMAN J. (1992). Interferon alfa-2a therapy for life-threatening hemangiomas of infancy. N Engl J Med. 326: 1456-1463.

FERNÁNDEZY, BERNABEU-WITTELM, GARCÍA-MORILLOJS. (2009). Kaposiform hemangioendothelioma. Eur J Intern Med 20: 106-113.

FOTSIST, ZHANG Y, PEPPERMS, ADLERCREUTZH, MONTESANO R, NAWROTH PP, SCHWEIGERER L. (1994). The endogenous oestrogen metabolite 2-methoxyoestradiol inhibits angiogenesis and suppresses tumour growth. Nature 368: 237-239

FREI-JONES M, MCKINSTRY RC, PERRY A, LEONARD JR, PARK TS, RUBIN JB. (2008). Use of thalidomide to diminish growth velocity in a life-threatening congenital intracranial hemangioma. J Neuros-Pediatr 2: 125-129.

FRIEDEN IJ, EICHENFIELD LF, ESTERLY NB, GERONEMUS R, MALLORY SB, THE GUIDELINES/OUTCOMES COMMITTEE. (1997). Guidelines of care for hemangiomas of infancy. J Am Acad Dermatol 37: 631-637.

GOTTSCHLING S, SCHNEIDER G, MEYER S, REINHARD H, DILL-MUELLER D, GRAFN. (2006). Two infants with life-threatening diffuse neonatal hemangiomatosis treated with cyclophosphamide. Pediatr Blood Cancer 46: 239-242.

GRIMAL I, DUVEAU E, ENJOLRAS O, VERRET JL, GINIES JL. (2000). Effectiveness and dangers of interferon-alpha in the treatment of severe hemangiomas in infants. Arch Pediatrie 7: 163-167.

HAIK BG, KARCIOGLU ZA, GORDON RA, PECHOUS BP. (1994). Capillary hemangioma (infantile periocular hemangioma). Surv Ophthalmol 38: 399-426.

HAJIGHASEMI F.H. MA. (2009). In vitro sensitivity of leukemia cells to propranolol. $J$ Clin Med Res 1: 144-149.

HASAN Q, TAN ST, XU B, DAVIS PF. (2003). Effects of five commonly used glucocorticoids on haemangioma in vitro. Clin Exp Pharmacol P 30: 140-144.

HASAN Q, ROGER BM, TAN ST, GUSH J, DAVIS PF. (2000). Clusterin/ApoJ expression during the development of hemangioma. Hum Pathol 31: 691-697.

HAYOT C, FARINELLE S, DE DECKER R, DECAESTECKER C, DARRO F, KISS R, VAN DAMME M. (2002). In vitro pharmacological characterizations of the anti-angiogenic and anti-tumor cell migration properties mediated by microtubuleaffecting drugs, with special emphasis on the organization of the actin cytoskeleton. Int J Oncol 21: 417-425.

JIMENEZ-HERNANDEZ E, DUENAS-GONZALEZ MT, QUINTERO-CURIEL JL, VELASQUEZ-ORTEGA J, MAGANA-PEREZ JA, BERGES-GARCIA A, ARELLANO-GALINDO J. (2008). Treatment with interferon-alpha-2b in children with life-threatening hemangiomas. Dermatol Surg 34: 640-647.

KOMOROWSKI J, JERCZYŃSKA H, SIEJKA A, BARAŃSKA P, ŁAWNICKA H, PAWŁOWSKA Z, STĘPIEŃ H. (2006). Effect of thalidomide affecting VEGF secretion, cell migration, adhesion and capillary tube formation of human endothelial EA.hy 926 cells. Life Sci 78(22): 2558-63.

KULLENDORFF CM. (1997). Efficacy of bleomycin treatment for symptomatic hemangiomas in children. Pediatr Surg Int 12: 526-528.

LÉAUTÉ-LABRĖZE C, DUMAS DE LA ROQUE E, HUBICHE T, BORALEVI F, THAMBO JB, TAÏEB A. (2008). Propranolol for severe hemangiomas of infancy. N Engl J Med 358: 2649-2651.

MABETA P, PEPPER MS. (2009). A comparative study on the anti-angiogenic effects of DNA-damaging and cytoskeletal-disrupting agents. Angiogenesis 12: 81-90.

MABETAP, DAVIS PF. (2008). The mechanism of bleomycin in inducing haemangioma regression. S Afr Med J 98: 538-539.

MARTINSAG. (1970). Hemangioma and thrombocytopenia. J Pediatr Surg5: 641-648.

MCKAY TL, GEDEON DJ, VICKERMAN MB, HYLTON AG, RIBITA D, OLAR HH, KAISER PK, PARSONS-WINGERTER P. (2008). Selective inhibition of angiogenesis in small blood vessels and decrease in vessel diameter throughout the vascular tree by triamcinolone acetonide. Invest Ophthalmol Vis Sci49:1184-1190.
MUIRT, KIRSTEN M, FOURIE P, DIPPENAARN, IONESCU GO. (2004). Intralesiona bleomycin injection (IBI) for hemangiomas and congenital vascular malformations. $J$ Pediatr Surg 39: 1735-1736.

MULLIKEN JB and ENJOLRAS O. (2004). Congenital hemangiomas and infantile hemangioma: Missing links. J Am Acad Dermatol 50: 875-882.

MULLIKEN JB and GLOWACKI J. (1982). Hemangiomas and vascular malformations in infants and children: A classification based on endothelial characteristics. Plast Reconstr Surg 69: 412-422.

MULLIKEN JB, ZETTER BR, FOLKMAN J. (1982). In vitro characteristics of endothelium from hemangiomas and vascular malformations. Surgery 92: 348-353.

NORTH PE, WANERM, BRODSKYMC. (2002). Are infantile hemangioma of placental origin? Ophthalmology 109: 223-224.

NORTHPE, WANERM, MIZERACKIA, MIHM MC. (2000). GLUT1:Anewly discovered immunohistochemical marker for juvenile hemangiomas. Hum Pathol 31: 11-22.

OIKAWA T, HIROTANI K, OGASAWARA H, KATAYAMA T, ASHINO-FUSE H, SHIMAMURA M, IWAGUCHI T, NAKAMURA O. (1990). Inhibition of angiogenesis by bleomycin and its copper complex. Chem Pharm Bull 38: 1790-1792.

PANDEY A, GANGOPADHYAY AN, UPADHYAY VD. (2008). Evaluation and management of infantile hemangioma: An overview. Ostomy Wound Manag 54: 16-18.

PANDEYA, GANGOPADHYAYAN, GOPALSC, KUMAR V, SHARMASP, GUPTADK SINHACK. (2009). Twenty years' experience of steroids in infantile hemangioma-a developing country's perspective. J Pediatr Surg 44: 688-694.

PEPPER MS. (1997). Manipulating angiogenesis. from basic science to the bedside. Arterioscl Thromb Vas 17: 605-619.

PEREZ PAYAROLS J, PARDO MASFERRER J, GOMEZ BELLVERT C. (1995). Treatment of life-threatening infantile hemangiomas with vincristine. $N$ Engl $J$ Med 333: 369 .

PIENAAR C, GRAHAM R, GELDENHUYS S, HUDSON DA. (2006). Intralesional bleomycin for the treatment of hemangiomas. Plast Reconstr Surg 117: 221-226.

RAIG ET, JONES NB, VARKER KA, BENNIGER K, GO MR, BIBER JL, LESINSKI GB, CARSON WE,3rd. (2008). VEGF secretion is inhibited by interferon-alpha in several melanoma cell lines. J. Interfer. Cytokine Res. 28: 553-561.

RAZON MJ, KRALING BM, MULLIKEN JB, BISCHOFF J. (1998). Increased apoptosis coincides with onset of involution in infantile hemangioma. Microcirculation 5: 189-195.

REGNIER S, DUPIN N, LE DANFF C, WASSEF M, ENJOLRAS O, ARACTINGI S. (2007). Endothelial cells in infantile haemangiomas originate from the child and not from the mother (a fluorescence in situ hybridization-based study). $\mathrm{Br} \mathrm{J}$ Dermatol 157: 158-160.

SANS V, DE LR, BERGE J, GRENIER N, BORALEVI F, MAZEREEUW-HAUTIER J, LIPSKER D, DUPUIS E, EZZEDINE K, VERGNES P, et al., (2009). Propranolo for severe infantile hemangiomas: Follow-up report. Pediatrics 124:e423-431.

SARIHAN H, MOCAN H, YILDIZ K, ABES M, AKYAZICI R. (1997). A new treatment with bleomycin for complicated cutaneous hemangioma in children. Eur J Pediatr Surg 7: 158-162.

SGONC R, FUERHAPTER C, BOECK G, SWERLICK R, FRITSCH P, SEPP N. (1998). Induction of apoptosis in human dermal microvascular endothelial cells and infantile hemangiomas by interferon-alpha. Int Arch Aller Imm 117: 209-214.

SOMMERS SMITH SK and SMITH DM. (2002). Beta blockade induces apoptosis in cultured capillary endothelial cells. In vitro Cell Dev B-An 38: 298-304.

TAKAHASHIK, MULLIKEN JB, KOZAKEWICH HP, ROGERS RA, FOLKMANJ, EZEKOWITZRA. (1994). Cellular markers that distinguish the phases of hemangioma during infancy and childhood. J Clin Invest 93: 2357-2364.

TAN ST, VELICKOVIC M, RUGER B, DAVIS PF. (2000). Cellular and Extracellular markers of hemangioma. Plast Reconstr Surg 106: 529-538.

VLAHOVIC A, SIMIC R, DJOKIC D, CERAN C. (2009). Diffuse neonatal hemangiomatosis treatment with cyclophosphamide: A case report. J Pediat Hemato Onc 31: 858-860.

WANG L, WU W, SUN H, WU X, QIN L, LIU Y, LIU K, TANG Z. (2003). Mechanism of interferon alpha on inhibition of metastasis and angiogenesis of hepatocellular carcinoma after curative resection in nude mice. J Gastrointest Surg 7: 587-594.

WILSON MW, HOEHN ME, HAIK BG, RIEMAN M, REISS U. (2007). Low-dose cyclophosphamide and interferon alfa 2a for the treatment of capillary hemangioma of the orbit. Ophthalmology 114: 1007-1011.

YANG Y, SUN M, CHENG X, HU X, ZHANG P, MA Q, LI J, TIAN L, LEI D. (2009). 
Bleomycin A5 plus dexamethasone for control of growth in infantile parotid hemangiomas. Oral Surg Oral Med O 108: 62-69.

ZAREM H.A. EDGERTONMT. (1967). Induced resolution of cavernous hemangiomas following prednisolone therapy. Plast Reconstr Surg 39: 76-83.

ZHANG G, YI C, LI X, LIANG Z, WANG R, LIU D, ZHANG L, MENG C, GUO S. (2008). Proliferation hemangiomas formation through dual mechanism of vascular endothelial growth factor mediated endothelial progenitor cells proliferation and mobilization through matrix metalloproteinases 9. Med Hypotheses 70: 815-818.
ZHANG Q, KANG X, ZHAO W. (2006). Antiangiogenic effect of low-dose cyclophosphamide combined with ginsenoside Rg3 on lewis lung carcinoma. Biochem Biophys Res Commun 342: 824-828.

ZHENG JW, YANG XJ, WANG YA, HE Y, YE WM, ZHANG ZY. (2009). Intralesional injection of pingyangmycin for vascular malformations in oral and maxillofacial regions: An evaluation of 297 consecutive patients. Oral Oncol 45: 872-876.

ZVULUNOV A, METZKER A. (2002). Hemangiomas and vascular malformations: Unapproved treatments. Clin Dermatol 20: 660-667. 


\section{Further Related Reading, published previously in the Int. J. Dev. Biol.}

The seminal work of Werner Risau in the study of the development of the vascular system Domenico Ribatti

Int. J. Dev. Biol. (2010) 54: 567-572

The contribution of Roberto Montesano to the study of interactions between epithelial sheets and the surrounding extracellular matrix Domenico Ribatti

Int. J. Dev. Biol. (2010) 54: 1-6

Parallels in invasion and angiogenesis provide pivotal points for therapeutic intervention Suzanne A. Eccles

Int. J. Dev. Biol. (2004) 48: 583-598

Angiogenesis and apoptosis are cellular parameters of neoplastic progression in transgenic mouse models of tumorigenesis. G Bergers, D Hanahan and L M Coussens Int. J. Dev. Biol. (1998) 42: 995-1002

5 yr ISI Impact Factor $(2009)=3.253$

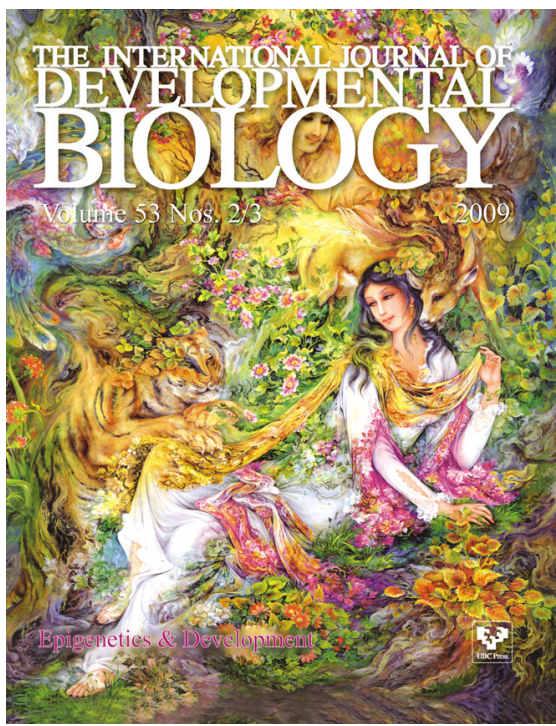

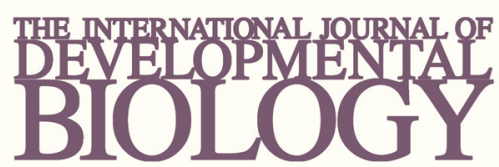

Volume 54 Nos. 6/7
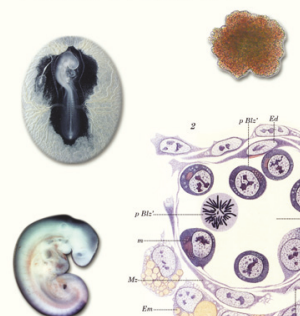

(2) (6)
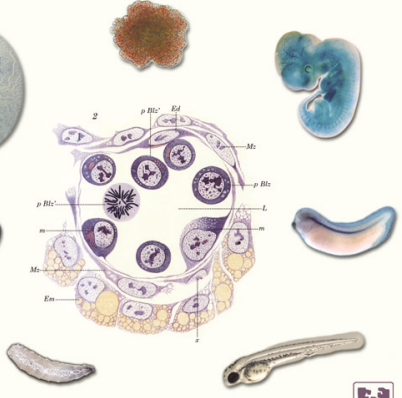

Developmental Hematopoiesis

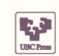

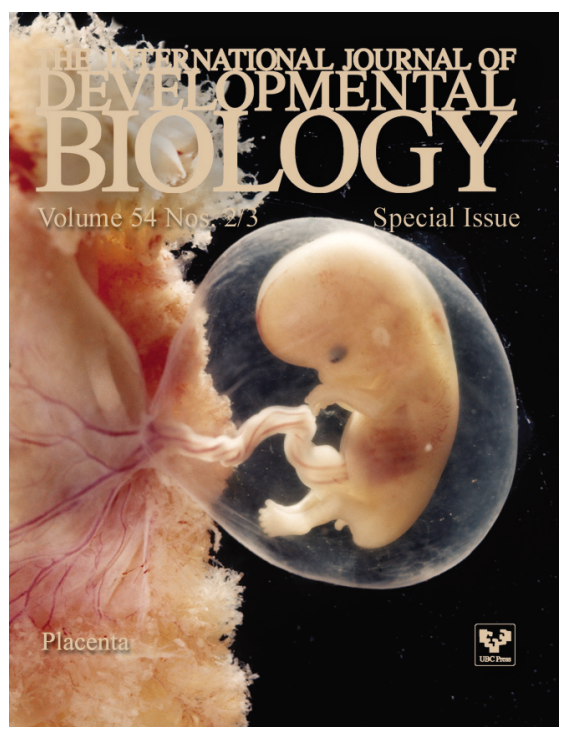

